A therapeutic alternative for fever

PediaProfen.

Ibuprofen Suspension $100 \mathrm{mg} / 5 \mathrm{ml}$ The following is a briet summary onky Before prescribing, see complete prescribing information in

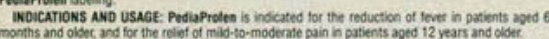

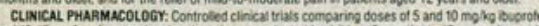

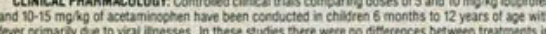

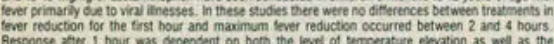

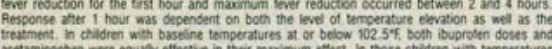

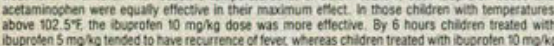

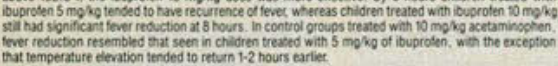

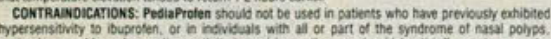

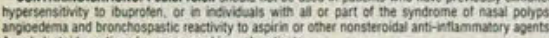

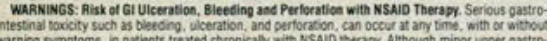

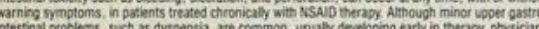

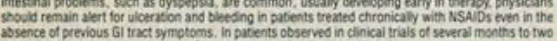

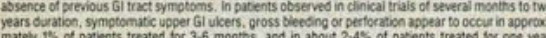

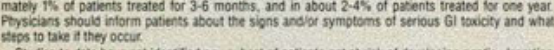

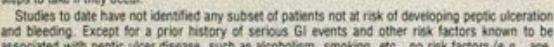

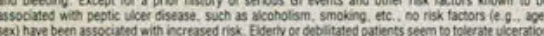

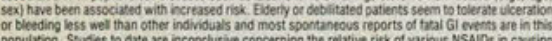
wech ceactions. High doses of ary ASAID probiaty carry a greater nisk of these resctions, athove controded cinical trials showing this do not exist $h$ most cases. $h$ considerng the use of reativel Iarge doses (within the recommended dos:

PRECAUTONS: Generat: Bivred and or diminished vision, scotomata, andor changes in colot

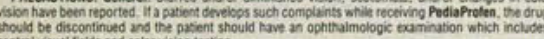
centra visual fietss and color vision lesting

Ald retention and edema hwe been reported in association weh bupsofent theretore, the orus

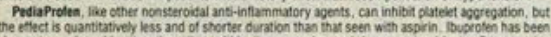
the ethect is quantitatively less and of storter duration than ihat seen with asporin. buckoten has been

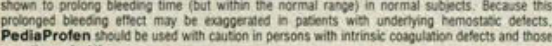

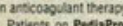

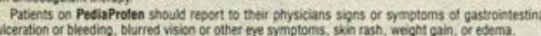

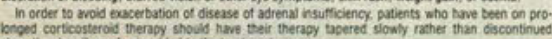

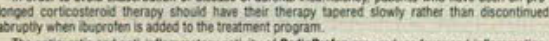

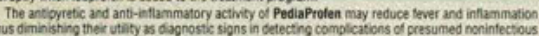
Astammatry pantul conditions

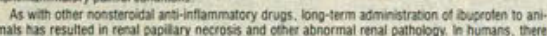
mals nas resulted in resal capilary necrosis and ceter abnormal renal patholiogy in humans, thete:

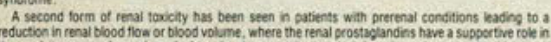

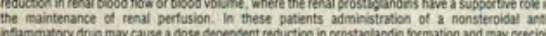

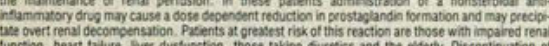

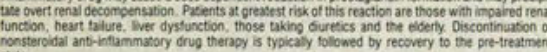

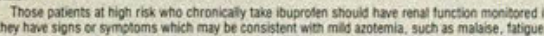
they have signs or symbloms which may be consistent with mild azotemia, such as malaise, tatigue. coves without sions or symptoms.

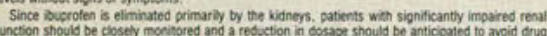

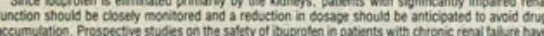
cot been conducted.

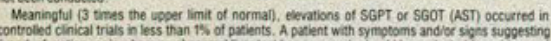

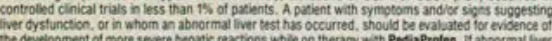

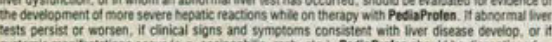

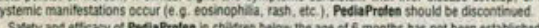

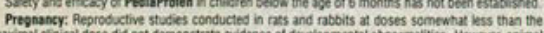

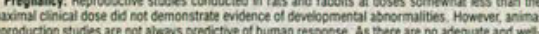
.

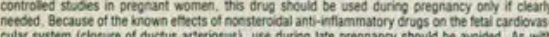
cular system (closure of ductus anteriosess), use durng ite pregnancy should be avcioged. As weth

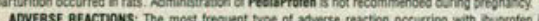

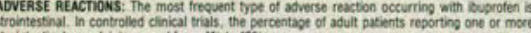
astrointestinal complants nanged from 4 s, to 16 \%

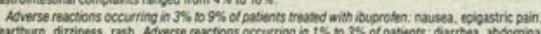

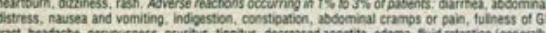

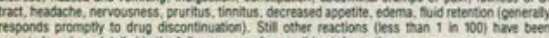
eported. and are decailed in the full summary of prescribing intormation.

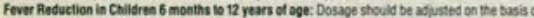

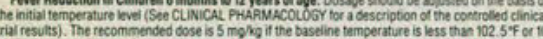

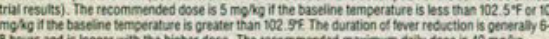

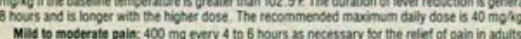

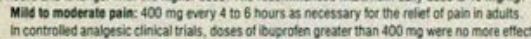
In controlied analy

than 400 mo dose.

orange, berry-vanila flavored

Bothes of 4 or $(120 \mathrm{mi})$.

Conting. Stoce at room temperature.

MENEIL CONSUMER PRODUCTS CO.

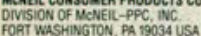

NOC $0045-0469-04$ NoC $0045-0469-16$

\title{
Incorporating OMT in hospital training
}

\section{To the Editor:}

My compliments to the editors for featuring an article ("Osteopathic interns' attitudes toward their education and training") and an editorial ("Osteopathic medical educators should heed lessons from interns") concerning osteopathic medical education in the August issue of the JAOA (1991;91:786-802,748, 750). Both of these writings address the current state of osteopathic medical training. I would like to add my own insights in this area.

After more than 25 years as a general practitioner of osteopathic medicine, I have entered the field of teaching osteopathic manipulative techniques. It has been my observation that after 2 years in an osteopathic medical college most students have a pretty good idea of how to give "patients" osteopathic manipulative treatment (OMT). Some credit for this achievement should go, in part, to the Educational Council on Osteopathic Principles (ECOP). Established by the American Osteopathic Association (AOA), the ECOP is composed of educators from the various colleges of osteopathic medicine. These professors meet regularly to share ideas and concepts on teaching osteopathic medical techniques and principles.

Yet, more needs to be done. While having the privilege to serve on the Committee on Hospital Accreditation recently, I became aware of how few hospitalized patients receive OMT. At the same time, I was impressed with the various specialists and their close attention to the interns' conduct when the interns are dealing with patients. Surgeons explain to interns how to scrub, gown, and glove for surgery; they closely supervise the interns' conduct at the operating table. Such attention is true of other specialists, including obstetricians.

Given this attention, I think that if our hospitals had OMT specialists on staff to teach and supervise interns in this area, these physicians would become more proficient in using these techniques. After all, OMT requires kinetic or manual dexterity, similar to that needed in handling a surgical instrument or delivering a baby. Such hospitalbased specialists could ensure that interns receive adequate instruction and provide OMT. These specialists would also serve as role models.

The AOA could institute such a program under the auspices of a committee similar to the ECOP. This arrangement would ensure uniformity of intern training in the clinical application of osteopathic manipulative skills.

GERALD J. COOPER, DO

Associate Professor

Department of Osteopathic Manipulative Medicine

University of Osteopathic Medicine and Health Sciences

Des Moines, Iowa 